\title{
Apolipoprotein E4 is only a weak predictor of dementia and cognitive decline in the general population
}

\author{
A G Yip, C Brayne, D Easton, D C Rubinsztein, the Medical Research Council Cognitive \\ Function and Ageing Study (MRC CFAS)
}

\begin{abstract}
Background: Apolipoprotein E (APOE) polymorphisms are unequivocally associated with risk for Alzheimer's disease (AD). It is crucial to understand how this genetic factor affects dementia risk in the general population, as well as in narrowly diagnosed, selected, patient groups.

Methods: We assessed the cross sectional association between $A P O E$ genotype and dementia status in a community based sample, the MRC Cognitive Function and Ageing Study (MRC CFAS). In addi-

tion, we tested the effects of APOE genotypes on the differences in MMSE scores between the first and third assessment waves (about six years apart), an index of cognitive decline.

Results: The APOE $\epsilon 4$ allele conferred increased risk for dementia $(\mathrm{OR}=1.5,95 \% \mathrm{Cl}=1.1$ to 2.2$) \mathrm{com}$ pared to $\epsilon 3$ in the MRC CFAS sample. Compared with APOE $\epsilon 3 / \epsilon 3$ subjects, those with the $\epsilon 3 / \epsilon 4$ genotypes were not at significantly higher risk for dementia ( $\mathrm{OR}=1.1,95 \% \mathrm{Cl}=0.6$ to 1.9), although $\epsilon 4 / \epsilon 4$ subjects were $(\mathrm{OR}=3.8,95 \% \mathrm{Cl}=1.0$ to 14.0$)$. Risk estimates were not different between men and women. Notably, our risk estimates for dementia were significantly lower than those reported for a diagnosis of Alzheimer's disease. MMSE scores at wave 3 and the difference in MMSE between baseline and at the third assessment wave were not different across APOE genotypes.

Interpretation: The $A P O E \epsilon 4$ allele is a weaker predictor for dementia in the general population than for $A D$. This may be because dementia can be caused by non-AD pathological processes and because most prevalent dementia occurs at an age when the $A P O E \in 4$ effect on $A D$ risk (and therefore dementia) has started to decline.
\end{abstract}

Correspondence to:

Dr D C Rubinsztein,

Department of Medical

Genetics, Cambridge

Institute for Medical

Research, Wellcome/MRC

Building, Addenbrooke's

Hospital, Hills Road,

Cambridge CB2 2XY, UK;

dcr1000@cus.cam.ac.uk

Revised version received

12 February 2002

Accepted for publication

10 May 2002
D ementia is the most common neurodegenerative condition affecting older people. It is estimated that around 550000 people aged 65 years and over in England and Wales are suffering from dementia of mild or greater severity. ${ }^{1}$ Prevalence increases exponentially with age, from around $1 \%$ of 65 year olds to approximately $30 \%$ of people aged 85 years and older. ${ }^{2}$ Most cases $(60-70 \%)$ of incident dementia are clinically diagnosed as Alzheimer's disease, while $15-20 \%$ are accounted for by vascular dementia (VaD). ${ }^{3}$ However, Alzheimer-type and vascular pathology frequently occur in the same person, the neuropathological features associated with $\mathrm{AD}$ and $\mathrm{VaD}$ are present in many cognitively intact subjects, and some demented subjects do not have the neuropathological hallmarks of $\mathrm{AD}$ or VaD. ${ }^{4}$

Alzheimer's disease risk is unequivocally associated with polymorphisms in the apolipoprotein $\mathrm{E}(A P O E)$ gene (chromosome 19q13.2). ApoE (OMIM *107741) ${ }^{5}$ is a 299 amino acid plasma glycoprotein that plays a major role in lipoprotein metabolism as a ligand for receptors of the low density lipoprotein (LDL) receptor superfamily. Two polymorphisms in the coding region of $A P O E$ result in three major isoforms of the protein, apoE2, apoE3 (the most common isoform), and apoE4. Pooled results from association studies reported a 14-fold increased risk of $\mathrm{AD}$ for $A P O E \in 4$ homozygotes and a trebling of risk among $A P O E \in 3 / \in 4$ carriers compared with $\epsilon 3 / \epsilon 3$ subjects. ${ }^{67}$

We believe that the public are primarily concerned about their risk for dementia in general, in addition to the specific risks for AD or VaD. Similarly, from a public health perspective, it is crucial to understand how a genetic factor as important as APOE affects dementia in the general population as well as among narrowly diagnosed, selected, patient groups.

Thus, we have investigated the effect of APOE on dementia and cognitive decline risk in elderly populations across England and Wales drawn from a multicentre, population based, longitudinal study of ageing and cognitive and functional status (the MRC Cognitive Function and Ageing Study).

\section{METHODS \\ Sample}

The MRC Cognitive Function and Ageing Study is a multicentre, prospective study into the functional and cognitive status of the elderly in England and Wales. The centres used for the present analyses are set in two rural (Cambridgeshire and Gwynedd) and two urban (Nottingham and Newcastle) locations. A detailed description of the design of the study has been published elsewhere. ${ }^{1}$ Briefly, a two phase sampling design was used, where stratification for probability sampling for assessment was based on age and performance on dementia screening tests (Automated Geriatric Examination for Computer Assisted Taxonomy (AGECAT) $\operatorname{organicity~items~}^{8}$ and the Mini Mental State Examination ${ }^{9}$ ). A total of 2034 subjects out of 10264 screened were sampled for assessment in this way. The assessed respondents then underwent two further follow up interviews to ascertain incident cases. Those not sampled in the first (prevalence) wave were screened during the second wave (two years later), and were selected for assessment using the same probability sampling scheme (5618 screened, 1151 assessed). Thus, $2034+1151=$ 3185 subjects were selected for assessment over these two waves. At the third wave (approximately six years into the

Abbreviations: $A P O E$, apolipoprotein $E ; A D$, Alzheimer's disease; MRC CFAS, Medical Research Council Cognitive Function and Ageing Study; $\mathrm{VaD}$, vascular dementia; LDL, low density lipoprotein; MMSE, Mini Mental State Examination; AGECAT, Automated Geriatric Examination for Computer Based Taxonomy; OR, odds ratio 
Table 1 Allele and genotype frequencies at the APOE locus among demented and non-demented CFAS subjects, overall

\begin{tabular}{|c|c|c|c|c|c|c|c|}
\hline & \multirow[b]{2}{*}{ Controls } & \multirow[b]{2}{*}{ Cases } & \multirow[b]{2}{*}{ Crude OR $(95 \% \mathrm{Cl})$} & \multirow{2}{*}{$\begin{array}{l}\text { Adjusted* OR (95\% } \\
\text { CI) }\end{array}$} & \multirow{2}{*}{$\begin{array}{l}\text { Rubinsztein and } \\
\text { Easton } 7 \dagger\end{array}$} & \multicolumn{2}{|l|}{ Farrer et $a l^{\circ} \ddagger$} \\
\hline & & & & & & Population based & Clinic/necropsy \\
\hline \multicolumn{8}{|l|}{ Allele } \\
\hline$\epsilon 3$ & 722 & 246 & 1.0 & 1.0 & 1.0 & & \\
\hline$\epsilon 2$ & 85 & 26 & $0.9(0.6$ to 1.4$)$ & $0.7(0.4$ to 1.2$)$ & $0.7(0.6$ to 0.8$)$ & & \\
\hline$\epsilon 4$ & 125 & 52 & $1.2(0.9$ to 1.7$)$ & 1.5 (1.1 to 2.2$)$ & $3.4(3.0$ to 3.6$)$ & & \\
\hline \multicolumn{8}{|l|}{ Genotype } \\
\hline$\epsilon 3 / \epsilon 3$ & 277 & 97 & 1.0 & 1.0 & 1.0 & 1.0 & 1.0 \\
\hline$\epsilon 2 / \epsilon 2$ & 4 & 3 & 2.1 (0.5 to 9.7) & $0.5(0.1$ to 5.2$)$ & $0.9(0.4$ to 2.0$)$ & $0.9(0.3$ to 2.8$)$ & $0.6(0.2$ to 2.0$)$ \\
\hline$\epsilon 2 / \epsilon 3$ & 67 & 15 & $0.6(0.3$ to 1.2$)$ & $0.5(0.2$ to 1.2$)$ & $0.6(0.5$ to 0.7$)$ & $0.6(0.5$ to 0.9$)$ & $0.6(0.5$ to 0.8$)$ \\
\hline$\epsilon 2 / \epsilon 4$ & 10 & 5 & $1.4(0.5$ to 4.3$)$ & $1.7(0.4$ to 6.6$)$ & $1.9(1.3$ to 2.8$)$ & $1.2(0.8$ to 2.0$)$ & $2.6(1.6$ to 4.0$)$ \\
\hline$\epsilon 3 / \epsilon 4$ & 101 & 37 & $1.0(0.7$ to 1.6$)$ & 1.1 (0.6 to 1.9$)$ & 3.4 (3.0 to 3.9 ) & 2.7 (2.2 to 3.2$)$ & $3.2(2.8$ to 3.8$)$ \\
\hline$\epsilon 4 / \epsilon 4$ & 7 & 5 & $2.0(0.6$ to 6.6$)$ & $3.8(1.0$ to 14.0$)$ & $13.3(9.9$ to 17.9$)$ & 12.5 (8.8 to 17.7$)$ & $14.9(10.8$ to 20.6$)$ \\
\hline
\end{tabular}

study), a combined screen and assessment was completed on 1730 of this cohort who were still alive, accessible, and who had consented to remain in the study. Of this number, 1070 consented to give a blood sample or buccal swab for genetic studies.

\section{Assessment}

Respondents were assessed by trained interviewers from professions allied to medicine. The assessment interview provides information processed by the computer algorithm AGECAT, which generates a diagnosis of dementia (as well as affective and anxiety disorders) on the basis of criteria compatible with those of the International Classification of Diseases, 9th revision (ICD-9 $)^{10}$ and the Diagnostic and Statistical Manual (DSM-IIIR). ${ }^{11}$ Dementia is diagnosed if a person has an AGECAT organicity rating of $\mathrm{O} 3$ or above, which is highly correlated with clinical assessment of dementia status. ${ }^{8}$

Cases comprised all blood/saliva contributing participants who had been assigned an AGECAT organicity level of $\mathrm{O} 3$ or higher at any point during the three assessment waves and an MMSE score of 21 or less at the third assessment wave. The control group comprised subjects with AGECAT organicity level below $\mathrm{O} 3$ and an MMSE score of 26 or greater at the third assessment wave. Cases and controls were drawn from the 1030 subjects with known APOE genotypes.

There were 162 cases $($ male $=45$ : median age at wave $3=$ 81 years, 25 th centile $=76$ years, 75 th centile $=88$ years; female $=117$ : median age at wave $3=87$ years, 25 th centile $=82$ years, 75 th centile $=89$ years) and 466 controls (male $=$ 227: median age at wave $3=75$ years, 25 th centile $=72$ years, 75 th centile $=79$ years; female $=239$ : median age at wave $3=$ 76 years, 25 th centile $=72$ years, 75 th centile $=81$ years) for the APOE analyses.

\section{Genotyping}

$A P O E$ genotyping was performed as described by Wenham et al. ${ }^{12}$ All genotyping was carried out by the first author (AY), and genotype assignments double checked for accuracy by an expert (DCR). Samples with ambiguous genotypes were rerun. Three genotyping attempts were performed for each sample, after which the APOE status of unsuccessfully typed samples were recorded as unknown/failed. Apolipoprotein E (APOE) genotype was successfully determined in 1030 subjects (96.3\% of those with DNA samples).

\section{Analysis}

The association between APOE and dementia risk was examined by unconditional logistic regression. The analyses were conducted with third wave data only, to examine the cross sectional association between APOE and dementia risk, adjusting for age, sex, and years in full time education. Separate analyses for men and women, controlling for age and years in full time education were also carried out. The categorical variable APOE was classified by genotype: $\epsilon 3 / \epsilon 3$ (the reference group), $\epsilon 2 / \epsilon 2, \epsilon 2 / \epsilon 3, \in 2 / \epsilon 4, \epsilon 3 / \epsilon 4$, and $\epsilon 4 / \epsilon 4$. Additionally, odds ratios were calculated for alleles $\epsilon 2$ and $\epsilon 4$ relative to $\epsilon 3$. This analysis assumes that the maternal and paternal alleles act multiplicatively on risk so that, for example, the odds ratio associated with $\epsilon 2 / \epsilon 4$ relative to $\epsilon 3 / \epsilon 3$ is the product of the odds ratios of $\epsilon 2$ and $\epsilon 4$. Under this model the two alleles from the same subject can be analysed as if independent. Risk estimates based on genotype do not assume multiplicativity of allele risk. ${ }^{7}$ The $z$ test was used to compare the odds ratios we obtained with those reported in the metaanalysis of Rubinsztein and Easton. ${ }^{7}$

Because of the negatively skewed distribution of MMSE, individual scores at wave 3 were $\log$ transformed $\left[\mathrm{MMSE}_{\text {transformed }}=\log _{\mathrm{e}}(31-\mathrm{MMSE})\right]$, pooled by genotype, and then compared using analysis of variance (cross adjusting for genotype, age, sex, and number of years in full time education). The mean transformed MMSE score of each $A P O E$ genotype was back transformed $\left[\mathrm{MMSE}_{\text {original }}=31-\exp (\right.$ mean $\left.\mathrm{MMSE}_{\text {transformed }}\right)$ ] to return mean scores to their original scale.

Dementia prevalences were similar between the different centres. ${ }^{1}$ Furthermore, an overwhelming majority (if not all) of subjects are of white British origin, born before 1930, well before widespread immigration to the UK. Accordingly, we have not stratified our analysis by centre.

We used the difference in MMSE between score at baseline and at the third assessment wave as an index of cognitive decline. The Kruskal-Wallis test was used to compare the distributions of MMSE differences across the different $A P O E$ genotype groups.

\section{RESULTS}

Table 1 shows the distribution of APOE genotype and allele frequencies for cases and controls, as well as crude and adjusted (for age, sex, and years in full time education) odds ratios. The $A P O E \in 4$ allele confers moderately increased risk for dementia $(\mathrm{OR}=1.5,95 \% \mathrm{CI}=1.1$ to 2.2$)$ in the MRC CFAS sample. However, this odds ratio estimate is lower than the pooled OR estimate for Alzheimer's disease drawn from clinic and necropsy based studies ${ }^{7}(\epsilon 3 / \epsilon 4 \quad z=3.8, \mathrm{p}=0.01 ; \epsilon 4 / \epsilon 4$ $z=10.5, \mathrm{p}<0.01)$. APOE $\in 4 / \epsilon 4$ subjects were at significantly increased risk of dementia compared to those with $A P O E \in 3 / \epsilon 3$ $(\mathrm{OR}=3.8,95 \% \mathrm{CI}=1.0$ to 14.0$)$. (While the crude $\mathrm{OR}$ for $A P O E$ $\epsilon 4 / \epsilon 4$ appears to be lower than the adjusted OR, the $95 \%$ CIs overlap. The difference in these ORs is largely attributable to the effects of age.) $A P O E \in 3 / \epsilon 4$ subjects, however, were not at 


\begin{tabular}{|c|c|c|c|c|c|c|c|c|}
\hline & \multicolumn{4}{|l|}{ Male } & \multicolumn{4}{|l|}{ Female } \\
\hline & Cases & Controls & Crude OR $(95 \% \mathrm{Cl})$ & $\begin{array}{l}\text { Adjusted* OR } \\
(95 \% \mathrm{CI})\end{array}$ & Cases & Controls & Crude OR $(95 \% \mathrm{Cl})$ & $\begin{array}{l}\text { Adjusted* OR } \\
(95 \% \mathrm{CI})\end{array}$ \\
\hline \multicolumn{9}{|l|}{ Allele } \\
\hline$\epsilon 3$ & 69 & 360 & 1.0 & 1.0 & 177 & 362 & 1.0 & 1.0 \\
\hline$\epsilon 2$ & 7 & 38 & $1.0(0.4$ to 2.2$)$ & $0.7(0.3$ to 2.0$)$ & 19 & 47 & $0.8(0.5$ to 1.5$)$ & $0.6(0.3$ to 1.4$)$ \\
\hline$\epsilon 4$ & 14 & 56 & $1.3(0.7$ to 2.5$)$ & $1.3(0.6$ to 2.8$)$ & 38 & 69 & $1.1(0.7$ to 1.7$)$ & $1.6(0.9$ to 2.7$)$ \\
\hline \multicolumn{9}{|l|}{ Genotype } \\
\hline$\epsilon 3 / \epsilon 3$ & 27 & 140 & 1.0 & 1.0 & 70 & 137 & 1.0 & 1.0 \\
\hline$\epsilon 2 / \epsilon 2$ & 0 & 1 & - & - & 3 & 3 & $2.0(0.4$ to 9.9$)$ & $0.7(0.0$ to 10.8$)$ \\
\hline$\epsilon 2 / \epsilon 3$ & 5 & 32 & 0.8 (0.3 to 2.3$)$ & $0.6(0.2$ to 2.1$)$ & 10 & 35 & $0.6(0.3$ to 1.2$)$ & $0.5(0.2$ to 1.4$)$ \\
\hline$\epsilon 2 / \epsilon 4$ & 2 & 4 & $2.6(0.5$ to 14.9$)$ & $1.9(0.3$ to 13.9$)$ & 3 & 6 & $1.0(0.2$ to 4.0$)$ & $1.5(0.2$ to 10.5$)$ \\
\hline$\epsilon 3 / \epsilon 4$ & 10 & 48 & $1.1(0.5$ to 2.4$)$ & $1.0(0.4$ to 2.4$)$ & 27 & 53 & $1.0(0.6$ to 1.7$)$ & $1.2(0.6$ to 2.5$)$ \\
\hline$\in 4 / \epsilon 4$ & 1 & 2 & $2.6(0.2$ to 29.6$)$ & $6.2(0.5$ to 74.3$)$ & 4 & 5 & $1.6(0.4$ to 6.0$)$ & 3.3 (0.7 to 14.7$)$ \\
\hline
\end{tabular}

*Adjusted for age and years of full time education.

increased risk $(\mathrm{OR}=1.1,95 \% \mathrm{CI}=0.6$ to 1.9$)$. Our dementia odds ratio estimates and $95 \% \mathrm{CI}$ for $\epsilon 3 / \epsilon 4$ were also lower and did not overlap those from other clinic/necropsy based or population based studies. ${ }^{67}$ Subjects possessing the $\epsilon 2$ allele had a lower risk of dementia, although, because of small numbers, the odds ratio was not significant. Sex specific analyses (table 2) did not show any differences in allele and gene effects between men and women.

The back transformed mean MMSE scores at wave 3 by APOE genotypes were: $\epsilon 3 / \epsilon 3=25.4, \epsilon 2 / \epsilon 2=24.4, \epsilon 2 / \epsilon 3=25.9$, $\epsilon 2 / \epsilon 4=25.2, \epsilon 3 / \epsilon 4=25.8$, and $\epsilon 4 / \epsilon 4=25$.2. MMSE scores at the third wave were not significantly different between $A P O E$ genotypes ( $\mathrm{F}$ score $(5 \mathrm{df})=0.2, \mathrm{p}=0.9$ ).

We were interested in the effects of APOE genotypes on the rate of cognitive decline, as measured by the MMSE difference between the initial and third assessment waves, in our entire sample. In one set of analyses, we compared the distribution of MMSE difference across APOE genotypes in the sample separated into four subgroups based on subjects' MMSE scores at the prevalence wave (namely, 0-17, 18-21, 22-25, and 26-30). We adopted this strategy, since a given difference in MMSE scores over time would have a different meaning depending on the starting MMSE score. Fig IA-D shows the distribution of the differences in MMSE scores between assessment waves 3 and 1 across APOE genotypes, according to baseline MMSE level.

In another analysis, we looked at the distribution of MMSE difference across the different APOE genotypes among subjects scoring between 22 and 25 and between 26 and 30 on the MMSE at wave 3. This strategy was used to see whether $A P O E$ genotypes affected the rate of cognitive decline in subjects who were ostensibly non-demented throughout the
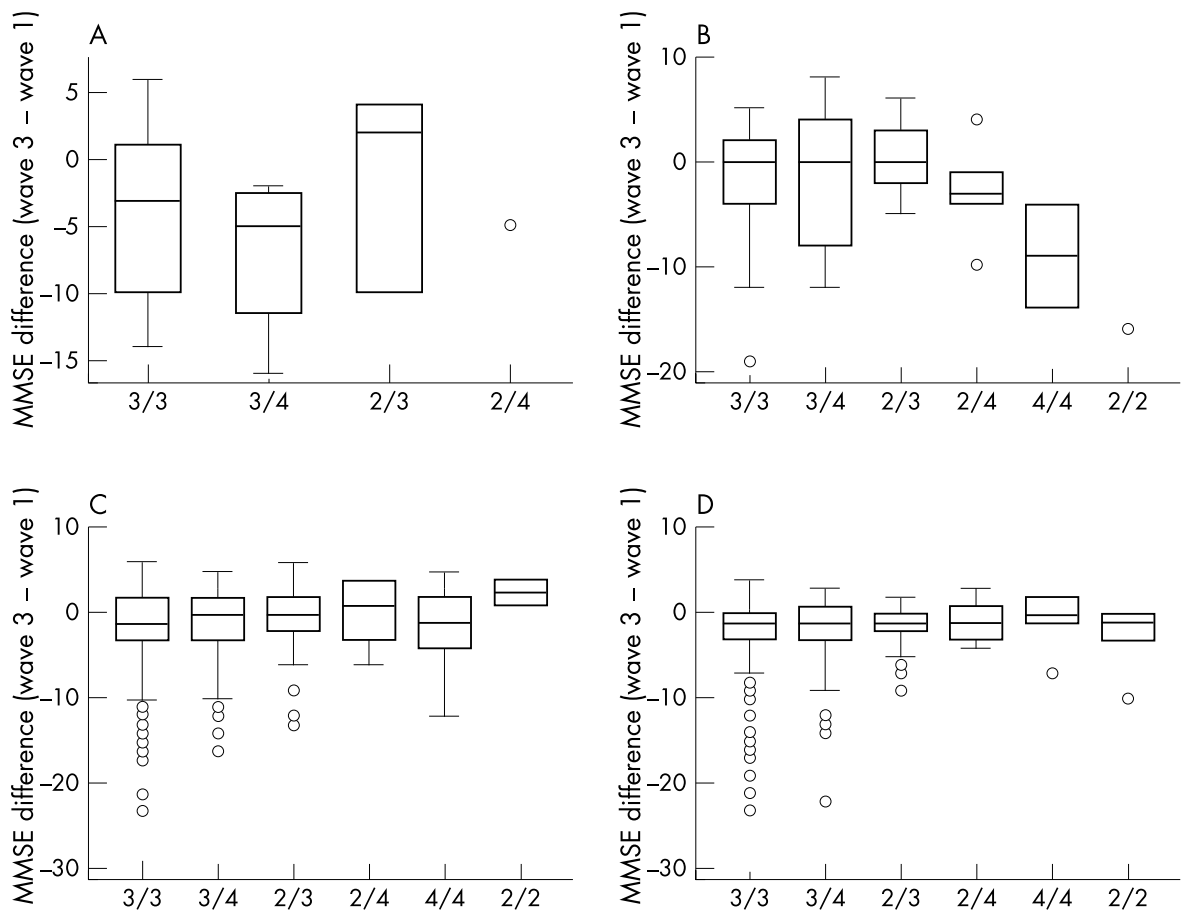

Figure 1 Distribution of MMSE difference (wave 3-wave 1) by APOE genotype, stratified by baseline MMSE score. (A) Baseline MMSE 17 or less (numbers included: $\epsilon 3 / \epsilon 3=23, \epsilon 3 / \epsilon 4=4, \epsilon 2 / \epsilon 3=3, \epsilon 2 / \epsilon 4=1$ ), Kruskal-Wallis statistic $\left(\chi^{2}, 3 \mathrm{df}\right)=1.9, p=0.6$. (B) Baseline MMSE 17-2 1 (numbers included: $\epsilon 3 / \epsilon 3=55, \epsilon 3 / \epsilon 4=14, \epsilon 2 / \epsilon 3=13, \epsilon 2 / \epsilon 4=5, \epsilon 4 / \epsilon 4=2, \epsilon 2 / \epsilon 2=1$ ), Kruskal-Wallis statistic $\left(\chi^{2}, 5 \mathrm{df}\right)=7.4, p=0.2$. (C) Baseline MMSE $22-25$ (numbers included: $\epsilon 3 / \epsilon 3=213, \epsilon 3 / \epsilon 4=70, \epsilon 2 / \epsilon 3=47, \epsilon 2 / \epsilon 4=7, \epsilon 4 / \epsilon 4=10, \epsilon 2 / \epsilon 2=2)$, Kruskal-Wallis statistic $\left(\chi^{2}, 5\right.$ $\mathrm{df}$ ) $=4.6, p=0.5$. (D) Baseline MMSE 26 and above (numbers included: $\epsilon 3 / \epsilon 3=315, \epsilon 3 / \epsilon 4=99, \epsilon 2 / \epsilon 3=68, \epsilon 2 / \epsilon 4=13, \epsilon 4 / \epsilon 4=6, \epsilon 2 / \epsilon 2=5$ ), Kruskal-Wallis statistic $\left(\chi^{2}, 5 \mathrm{df}\right)=3.0, p=0.7$. 


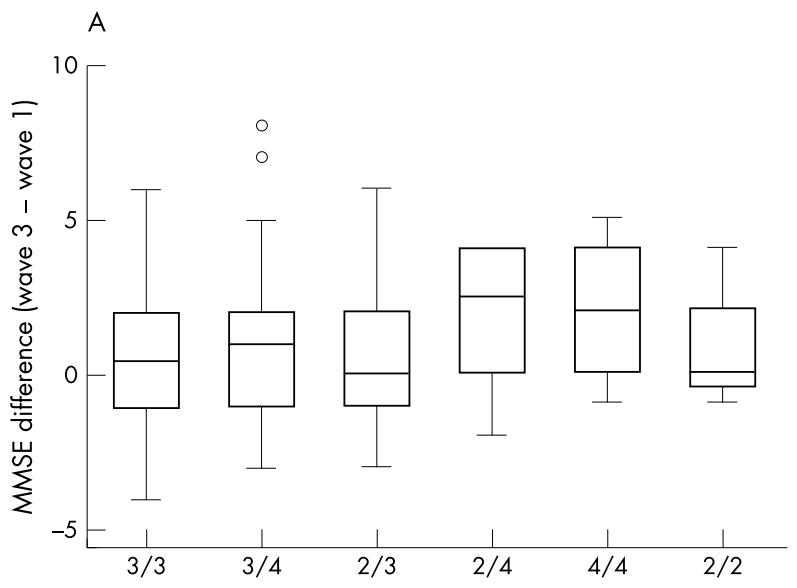

B

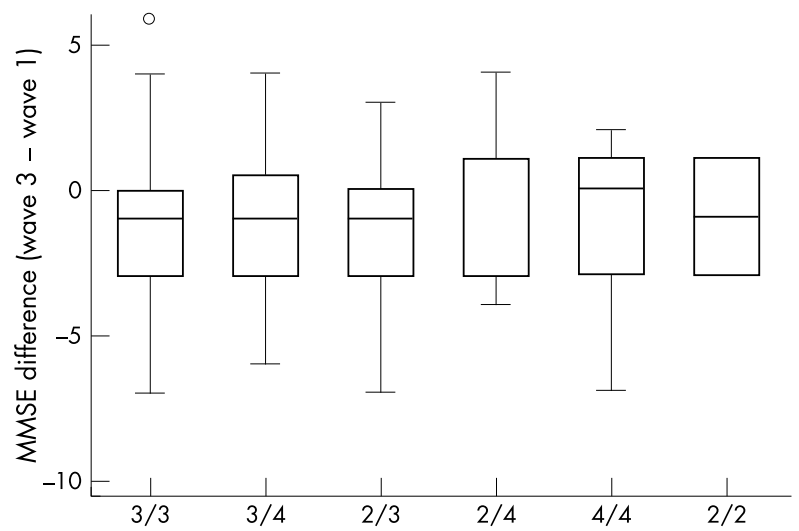

Figure 2 Distribution of MMSE difference by APOE genotype, stratified by wave 3 MMSE score. (A) MMSE wave 3 score 26-30 (numbers included: $\epsilon 3 / \epsilon 3=278, \epsilon 3 / \epsilon 4=101, \epsilon 2 / \epsilon 3=67$,

$\epsilon 2 / \epsilon 4=10, \epsilon 4 / \epsilon 4=7, \epsilon 2 / \epsilon 2=4)$, Kruskal-Wallis statistic $\left(\chi^{2}, 5 \mathrm{df}\right)=$ 4.6, $\mathrm{p}=0.5$. (B) MMSE wave 3 score $22-25$ (numbers included: $\epsilon 3 / \epsilon 3=180, \epsilon 3 / \epsilon 4=44, \epsilon 2 / \epsilon 3=35, \epsilon 2 / \epsilon 4=9, \epsilon 4 / \epsilon 4=5, \epsilon 2 / \epsilon 2=2)$, Kruskal-Wallis statistic $\left(\chi^{2}, 5 \mathrm{df}\right)=0.5, \mathrm{p}=0.9$.

study. In other words, we wanted to test if $A P O E$ affected the rate of cognitive decline before the onset of dementia. Fig 2A, $\mathrm{B}$ shows the MMSE difference across $A P O E$ genotypes among non-demented subjects at wave 3 who scored $22-25$ and 26 and over on the MMSE. There are no discernible differences across $A P O E$ genotypes when the sample was analysed using either strategy described above. Furthermore, $A P O E$ genotypes did not have any effect on change in MMSE score when the entire sample was analysed without any stratification (data not shown).

\section{DISCUSSION}

The aim of this study was to investigate the impact of APOE on dementia and cognitive decline in the general population. While a significant proportion of such demented cases have $\mathrm{AD}$, they also include people with vascular dementia, dementias of other aetiologies, and mixed dementias. This is in contrast with most published studies (both clinic/necropsy based and population based), which have looked into the impact of APOE on AD risk specifically, and have tended to use younger samples which may not reflect the population in which dementia occurs most frequently.

Our results confirm that the $A P O E \in 4$ allele significantly increases dementia risk (as opposed to a more restrictive diagnosis of $\mathrm{AD}$ ) in the general population by around $50 \%$. However, our risk estimates for the $\epsilon 4$ allele are significantly less for dementia than those generally reported for $\mathrm{AD}$ risk. Of particular importance, the $A P O E \in 3 / \epsilon 4$ genotype (the most common AD risk genotype) was not significantly associated with increased dementia risk $(\mathrm{OR}=1.1,95 \% \mathrm{CI}=0.6$ to 1.9$)$, although $\epsilon 4$ homozygotes are just under four times as likely to be demented as $\epsilon 3$ homozygotes (the reference group).

The MRC CFAS study uses AGECAT to diagnose dementia. It is a robust algorithm, with a high overall index of agreement $(\kappa=0.78)$ with psychiatrists' diagnoses in both the community and geriatric hospital settings (and excellent agreement regarding diagnosis of organic disorders, $\kappa=0.82) .{ }^{13}{ }^{14}$ It is possible that the impact of APOE $\epsilon 4$ is greatest for AD pathology and may have less importance for the other processes that contribute to dementia in the general population. It is interesting to note that the APOE $\epsilon 4$ odds ratios we observed were similar to those reported for all dementias in the population based Rotterdam study (OR $1.8,95 \%$ CI 1.2 to 2.7 ). ${ }^{15}$

The apparent discrepancies between our data and those of published meta-analyses may be because most demented subjects in the general population are in their eighth and ninth decades of life. Farrer et $a l^{6}$ reported that AD relative risks for $A P O E \in 3 / \epsilon 4$ and $\epsilon 4 / \epsilon 4$ decline with increasing age (and these are for clinic/necropsy based studies). For people 80 years old, the odds ratios (compared to $A P O E \epsilon 3 / \epsilon 3$ ) are 2.0 for $\epsilon 3 / \epsilon 4$ and 6.0 for $\epsilon 4 / \epsilon 4$. Among 85 year olds, the ORs are under 2.0 for $\epsilon 3 / \epsilon 4$ and around 4.0 for $\epsilon 4 / \epsilon 4$.

The incidence of Alzheimer's disease increases exponentially with age and more than half of all cases of AD occur among people older than 75 years. ${ }^{3}{ }^{16}$ In the UK population, $5.8 \%$ of demented subjects are aged between 65 and 69 years, $8.7 \%$ between 70 and $74,19 \%$ between 75 and $79,24 \%$ between 80 and 84 , and $43 \% 85$ years and over. ${ }^{1}$ The demented cases in the CFAS sample had a median age of 85 years (25th centile $=80$ years, 75 th centile $=89$ years ), and thus are fairly representative of cases of dementia in the general population.

Our results show that $A P O E$ genotypes are not associated with either cross sectionally determined cognitive function or cognitive decline as measured by the MMSE difference between baseline and last assessment wave. This finding is in agreement with a number of studies reporting no association between $A P O E$ genotype/allele and rate of cognitive decline or incidence of cognitive impairment among both $\mathrm{AD}$ patients and the non-demented elderly, ${ }^{17-24}$ although it appears that as many studies report increased rates of functional and cognitive decline among people with the APOE $\epsilon 4$ allele. ${ }^{25-29}$ Plassman and Breitner ${ }^{30}$ have commented on the possible reasons why studies failed to detect any differences in rate of decline among $\mathrm{AD}$ patients and the elderly in general. They point to non-linearity and individual variability in rates of pathogenesis, as well as the difficulties of controlling for all other determinants of neural reserve when examining trajectories of cognitive decline by $A P O E$ genotype. Furthermore, they point to the limitations of psychometric instruments used: neuropsychological performance is measured as a correlate of cognitive change, and tests tend to be less sensitive to change in subjects who have either mild or severe symptoms, and their scores do not vary in strict proportion to the underlying progression of the disease process. MMSE, for instance, as well as having documented ceiling and floor effects, provide ordinal and not ratio data, so that a three point decline from 19 to 16 is not necessarily equivalent to a decline from 27 to 24 . However, we stratified our sample by both initial and final MMSE scores and still no effects emerged for $A P O E$.

In conclusion, while $A P O E$ is unequivocally associated with Alzheimer's disease and is likely to play a key role in $\mathrm{AD}$ pathogenesis, our data suggest that its real influence on dementia risk in the general population may be smaller than that estimated for AD.

\section{ACKNOWLEDGEMENTS}

This work was supported by the Medical Research Council and the Department of Health. The authors thank the MRC CFAS respondents 
and their relatives for their participation in this long running project, and the MRC CFAS Internal Cambridge Advisory Group and Dr David Clayton for comments. AY is grateful to the Cambridge Overseas Trust and the European Dana Alliance for the Brain for funding. DCR is a Wellcome Trust Senior Research Fellow in Clinical Science.

\section{Authors' affiliations}

A G Yip, C Brayne, Department of Public Health and Primary Care, University Forvie Site, Robinson Way, Cambridge CB2 2SR, UK A G Yip, D C Rubinsztein, Department of Medical Genetics, Cambridge Institute for Medical Research, Wellcome/MRC Building, Addenbrooke's Hospital, Hills Road, Cambridge CB2 2XY, UK

D Easton, CRC Genetic Epidemiology Unit, Cambridge University Department of Public Health and Primary Care, Strangeways Research Laboratory, Worts' Causeway, Cambridge CBI 8RN, UK

\section{REFERENCES}

1 The Medical Research Council Cognitive Function and Ageing Study (MRC CFAS). Cognitive function and dementia in six areas of England and Wales: the distribution of MMSE and prevalence of GMS organicity level in the MRC CFA study. Psychol Med 1998:28:319-35.

2 Lobo A, Launer L, Fratiglioni L, Andersen K, Di Carlo A, Breteler MM Copeland JR, Dartigues JF, Jagger C, Martinez-Lage J, Soininen H, Hofman A. Prevalence of dementia and major subtypes in Europe: a collaborative study of population-based cohorts. Neurologic Diseases in the Elderly Research Group. Neurology 2000;54 (suppl 5):S4-9.

3 Fratiglioni L, Launer L, Andersen K, Breteler MM, Copeland JR, Dartigues JF, Lobo A, Martinez-Lage J, Soininen H, Hofman A. Incidence of dementia and major subtypes in Europe: a collaborative study of population-based cohorts. Neurologic Diseases in the Elderly Research Group. Neurology 2000;54(suppl 5):S10-15.

4 Neuropathology Group of the Medical Research Council Cognitive Function and Ageing Study (MRC CFAS). Pathological correlates of late-onset dementia in a multicentre, community-based population in England and Wales. Lancet 2001;357:169-75

5 Online Mendelian Inheritance in Man (OMIM). Apolipoprotein E. http://www3.ncbi.nlm.nih.gov/htbin-post/Omim/dispmim?107741. Accessed 31 July 2001.

6 Farrer LA, Cupples LA, Haines JL, Hyman B, Kukull WA, Mayeux R, Myers RH, Pericak-Vance MA, Risch N, van Duijn CM. Effects of age, sex, and ethnicity on the association between apolipoprotein $E$ genotype and Alzheimer disease. A meta-analysis. APOE and Alzheimer Disease Meta Analysis Consortium. JAMA 1997;278:1349-56.

7 Rubinsztein DC, Easton DF. Apolipoprotein E genetic variation and Alzheimer's disease. a meta-analysis. Dement Geriatr Cogn Disord 1999:10:199-209.

8 Copeland JRM, Dewey ME, Griffiths-Jones HM. Computerised psychiatric diagnostic system and case nomenclature for elderly subjects: GMS and AGECAT. Psychol Med 1986;16:89-99.

9 Folstein MF, Folstein SE, Hugh PR. Mini-mental state: a practical method for grading the cognitive state of patients for the clinician. J Psychiatr Res 1975;313:1419-20.

10 World Health Organization. Ninth revision of the international classification of diseases. Geneva: World Health Organization, 1977.

11 American Psychiatric Association. Diagnostic and statistical manual edition III revised. Washington, DC: American Psychiatric Association, 1987.
12 Wenham PR, Price WH, Blundell G. Apolipoprotein E genotyping by one-stage PCR. Lancet 1991;337:1 158-9.

13 Collinghan G, Macdonald A, Herzberg J, Philpot M, Lindesay J. An evaluation of the multidisciplinary approach to psychiatric diagnosis in elderly people. BM 1993;306:821-4.

14 Ames D, Flynn E, Tuckwell V, Harrigan S. Diagnosis of psychiatric disorder in elderly general and geriatric hospital patients: AGECAT and DSM-IIIR compared. Int J Geriatr Psychiatry 1994;9:627-33.

15 Hoffman A, Ott A, Breteler MMB, Bots ML, Slooter AJC, van Harskamp F, van Duijn C, Van Broekhoven C, Grobbee DE. Atherosclerosis, apolipoprotein $\mathrm{E}$, and prevalence of dementia and Alzheimer's disease in the Rotterdam Study. Lancet 1997;349:151-4.

16 Jorm AF, Jolley D. The incidence of dementia: a meta-analysis. Neurology 1998;51:728-33.

17 Basun H, Grut M. Winblad B, Lannfelt L. Apolipoprotein $\epsilon 4$ allele and disease progression in patients with late-onset Alzheimer's disease. Neurosci Lett 1995;183:32-4.

18 Murphy GMJ, Taylor JO, Kraemer HC, Yesavage J, Tinklenberg J. No association between apolipoprotein $\mathrm{E} \epsilon 4$ allele and rate of decline in Alzheimer's disease. Am J Psychiatry 1997; 154:603-8.

19 Growdon JH, Locascio JJ, Corkin S, Gomez-Isla T, Hyman BT. Apolipoprotein E genotype does not influence rates of cognitive decline in Alzheimer's disease. Neurology 1996;47:444-8.

20 Kurz A, Egensperger R, Haupt M, Lautenschlager NT, Romero B, Graeber MB, Muller U. Apolipoprotein E $\epsilon 4$ allele, cognitive decline, and deterioration of everyday performance in Alzheimer's disease. Neurology 1996;47:440-3.

21 Asada T, Kariya T, Yamagata Z, Kinoshita T, Asaka A. ApoE_ $\epsilon 4$ allele and cognitive decline in patients with Alzheimer's disease. Neurology 1996;47:603.

22 Hyman BT, Gomez-lsla T, Briggs M, Chung H, Nichols S, Kahout F, Wallace R. Apolipoprotein E and cognitive change in an elderly population. Ann Neurol 1996;40:55-66.

23 Small BJ, Graves AB, McEvoy CL, Crawford FC, Mullan M, Mortimer $J A$. Is APOE- $\epsilon 4$ a risk factor for cognitive impairment in normal aging? Neurology 2000;54:2082-8.

24 Juva K, Verkkoniemi A, Viramo P, Polvikoski T, Kainulainen K, Kontula $K$, Sulkava R. APOE $\epsilon 4$ does not predict mortality, cognitive decline, or dementia in the oldest old. Neurology 2000;54:412-15.

25 Craft S, Teri L, Edland SD, Kukull WA, Schellenberg G, McCormick WC, Bowen JD, Larson EB. Accelerated decline in apolipoprotein $E € 4$ homozygotes with Alzheimer's disease. Neurology 1998;51:149-53.

26 Small GW, Chen ST, Komo S, Ercoli L, Bookheimer S, Miller K, Lavretsky H, Saxena S, Kaplan A, Dorsey D, Scott WK, Saunders AM, Haines JL, Roses AD, Pericak-Vance MA. Memory and self-appraisal in middle-aged and older adults with the apolipoprotein E-4 allele. Am J Psychiatry 1999; 156:1035-8.

27 Caselli RJ, Graff-Radford NR, Reiman EM, Weaver A, Osborne D, Lucas J, Uecker A, Thibodeau SN. Preclinical memory decline in cognitively normal apolipoprotein $\mathrm{E}-\epsilon 4$ homozygotes. Neurology 1999;53:201-7.

28 Haan M, Shemanski L, Jagust WJ, Manolio TA, Kuller L. The role of APOE $\epsilon 4$ in modulating effects of other risk factors for cognitive decline in elderly persons. JAMA 1999;282:40-6.

29 Dik MG, Jonker C, Bouter LM, Geerlings MI, van Kamp GJ, Deeg DJ. APOE- $\epsilon 4$ is associated with memory decline in cognitively impaired elderly. Neurology 2000;54:1492-7.

30 Plassman BL, Breitner JC. Apolipoprotein E and cognitive decline in Alzheimer's disease. Neurology 1996;47:317-20. 